\title{
An immunocapture-LC-MS-based assay for serum SPINK1 allows simultaneous quantification and detection of SPINK1 variants
}

\section{Ravela, Suvi}

2018-02

Ravela , S , Valmu , L, Domanskyy , M , Koistinen , H , Kylänpää , L , Lindström , O , Stenman , J , Hämäläinen , E , Stenman , U-H \& Itkonen , O 2018 , 'An immunocapture-LC-MS-based assay for serum SPINK1 allows simultaneous quantification and detection of SPINK1 variants ' , Analytical and Bioanalytical Chemistry , vol. 410 , no. 6 , pp. 1679-1688 . https://doi.org/10.1007/s00216-017-0803-y

http://hdl.handle.net/10138/300355

https://doi.org/10.1007/s00216-017-0803-y

draft

Downloaded from Helda, University of Helsinki institutional repository.

This is an electronic reprint of the original article.

This reprint may differ from the original in pagination and typographic detail.

Please cite the original version. 


\title{
An immunocapture-LC-MS-based assay for serum SPINK1 allows simultaneous quantification and detection of SPINK1 variants
}

\author{
Suvi Ravela ${ }^{1,2} \cdot$ Leena Valmu $^{1,2} \cdot$ Mykola Domanskyy $^{1} \cdot$ Hannu Koistinen ${ }^{1} \cdot$ Leena Kylänpää $^{3} \cdot$ Outi Lindström $^{3}$. \\ Jakob Stenman $^{4,5}$. Esa Hämäläinen ${ }^{6}$. Ulf-Håkan Stenman ${ }^{1,6}$ • Outi Itkonen ${ }^{1,6}$
}

Received: 16 October 2017 / Revised: 27 November 2017 / Accepted: 1 December 2017 / Published online: 9 January 2018

(C) Springer-Verlag GmbH Germany, part of Springer Nature 2018

\begin{abstract}
Pancreatic secretory trypsin inhibitor Kazal type 1 (SPINK1) is a 6420 Da peptide produced by the pancreas, but also by several other tissues and many tumors. Some mutations of the SPINK1 gene, like the one causing amino acid change N34S, have been shown to confer susceptibility to recurrent or chronic pancreatitis. Detection of such variants are therefore of clinical utility. So far SPINK1 variants have been determined by DNA techniques. We have developed and validated an immunocapture-liquid chromatography-mass spectrometric (IC-LC-MS) assay for the detection and quantification of serum SPINK1, N34SSPINK1, and P55S-SPINK1. We compared this method with a time-resolved immunofluorometric assay (TR-IFMA) for serum samples and primer extension analysis of DNA samples. We used serum and DNA samples from patients with acute pancreatitis, renal cell carcinoma, or benign urological conditions. With the help of a zygosity score calculated from the respective peak areas using the formula wild-type (wt) SPINK1/(variant SPINK1 + wt SPINK1), we were able to correctly characterize the heterozygotes and homozygotes from the samples with DNA information. The score was then used to characterize the apparent zygosity of the samples with no DNA characterization. The IC-LC-MS method for SPINK1 was linear over the concentration range 0.5$1000 \mu \mathrm{g} / \mathrm{L}$. The limit of quantitation (LOQ) was $0.5 \mu \mathrm{g} / \mathrm{L}$. The IC-LC-MS and the TR-IFMA assays showed good correlation. The median zygosity score was 1.00 (95\% CI 0.98-1.01, $n=11$ ), 0.55 (95\% CI $0.43-0.61, n=14$ ), and 0.05 (range $0.04-0.07$, $n=3$ ) for individuals found to be wt, heterozygous, and homozygous, respectively, for the N34S-SPINK1 variant by DNA analysis. When DNA samples are not available, this assay facilitates identification of the N34S- and P55S-SPINK1 variants also in archival serum samples.
\end{abstract}

Keywords Immunocapture $\cdot$ TATI $\cdot$ SPINK1 $\cdot$ Quantitative LC-MS assay

Suvi Ravela

suvi.ravela@thermofisher.com

1 Department of Clinical Chemistry, University of Helsinki and Helsinki University Central Hospital, Haartmaninkatu 8, 00014 Helsinki, Finland

2 Present address: Thermo Fisher Scientific, Ratastie 2, 01620 Vantaa, Finland

3 Department of Surgery, Helsinki University Central Hospital, 00014 Helsinki, Finland

4 Institute for Molecular Medicine Finland, Tukholmankatu 8, 00014 Helsinki, Finland

5 Department of Women's and Children's Health, Karolinska Institutet, 17177 Stockholm, Sweden

6 HUSLAB, Helsinki University Central Hospital, 00014 Helsinki, Finland

\section{Introduction}

Serine peptidase inhibitor Kazal type 1 (SPINK1, also known as pancreatic secretory trypsin inhibitor or PSTI and tumorassociated trypsin inhibitor or TATI) is a $6240 \mathrm{Da}$ peptide that occurs at high concentrations in the pancreas and pancreatic fluid, where it represents 0.1 to $0.8 \%$ of the total protein [1]. The main function of SPINK1 in the pancreas is to serve as the first line of defense against premature activation of trypsinogens $[1,2]$. SPINK1 is also expressed in several other normal tissues, like the kidney [3], prostate [4], stomach, small intestine, and colon [5]. In these, SPINK1 may function as a growth factor, play a role in reproduction, or modulate apoptosis and normal tissue differentiation and repair [6]. SPINK1 is also expressed in several cancers [6, 7].

Pancreatitis may be induced by inadvertent activation of trypsinogens within the pancreas. It is characterized by 
inflammation and necrosis with swelling of pancreatic cells and organelles, and loss of plasma membrane integrity. This leads to increased leakage of pancreatic enzymes and SPINK1 into circulation. As a result, the concentrations of SPINK1 and trypsinogens in plasma and urine may increase more than 100 -fold [8-10]. The sensitivities of serum SPINK1, amylase, and elastase $I$ in acute pancreatitis (AP) are similar [11], but because SPINK1 also acts as an acute phase reactant [12], it has not replaced the amylase assay in routine diagnostics of AP. There are several known mutations in the SPINK1 gene which also alter the amino acid sequence $[13,14]$. The incidence of the most common variants N34S (6214 Da, dbSNP:rs17107315) and P55S (6231 Da, dbSNP:rs111966833) is 0.5-2.5\% [15, 16] and $0.5-3 \%$ [14-17], respectively. However, in chronic pancreatitis (CP) patients, the respective incidences are 9.1-28.6\% [16, 18-22] and 0.9-7.3\% [15-17, 21]. In a Finnish population, the N34S variant was found in $7.8 \%$ of AP patients, but there was no difference in the frequency of the P55S variant between the patients and controls [21]. The mechanism behind the association of the N34S variant with pancreatitis is not clear, because it is not known to alter expression, affinity for trypsin, or trypsin inhibitory activity [23-25].

Previously described enzyme-linked immunosorbent assays (ELISAs) [26-28], a time-resolved immunofluorometric assay (TR-IFMA) [28, 29], and radioimmunoassays (RIAs) [7, 10] for SPINK1 are based on antibodies, which are not known to distinguish between different SPINK1 variants. We describe here a novel assay based on immunocapture of SPINK1 from serum and detection and simultaneous quantification of wildtype (wt) SPINK1, N34S-, and P55S-SPINK1 variants by liquid chromatography-mass spectrometry (IC-LC-MS).

\section{Materials and methods}

\section{Samples}

We used serum samples from patients with benign urological conditions, with renal cell carcinoma, and suspicion of AP. In addition, we analyzed serum samples from patients $(n=34)$ with known SPINK1 variations confirmed by PCR amplification and minisequencing [21]. AP was diagnosed as described [30] at the Department of Surgery of Helsinki University Central Hospital. Samples from AP patients were collected during 2010-2012, from renal cell carcinoma (RCC) patients and benign controls during 2004-2006 and AP patients with known SPINK1 variations during 1998-2004, except for one sample that was collected in 2008. Patient characteristics are described in the Table 1 . All samples were stored at $-20{ }^{\circ} \mathrm{C}$ until analysis. Serum from an apparently healthy individual was used as low level $(11.2 \mu \mathrm{g} / \mathrm{L})$ and, when spiked with SPINK1 (63.4 $\mu \mathrm{g} / \mathrm{L})$, as high level quality assurance (QA) sample. The QA samples were aliquoted and stored at -
$80{ }^{\circ} \mathrm{C}$. The study was approved by the ethical committee of Helsinki University Central Hospital, Finland. Informed consent was obtained from all individuals.

\section{Production of calibrator and internal standard}

Synthetic cDNAs encoding different SPINK1 forms and optimized for expression in Escherichia coli were from GenScript. For the production of SPINK1 calibrator, we used a cDNA encoding wt SPINK1 (Uniprot: P00995) and for an internal standard a cDNA encoding SPINK1 with an S25Tmutation (Fig. 1). Both cDNAs lacked the part encoding signal peptide (amino acids 1-23). The SUMOstar Expression System (LifeSensors) was used for expression and purification of both wt and S24T-mutated SPINK1 peptides in house. Synthetic cDNA sequences were cloned into $\mathrm{pE}$ SUMOstar(Kn) vector and expressed in E. coli as fusion proteins with an N-terminal SUMO protein carrying a His-tag at the N-terminus. For peptide expression, E. coli BL21 (DE3) cells (Novagen) were induced overnight with $0.5 \mathrm{mM}$ isopropylthio- $\beta$-galactoside (Calbiochem) after the optical density reading at $600 \mathrm{~nm}$ of cell suspension reached 0.6. The synthesized His-tagged peptides were purified using NiNTA agarose (QIAGEN) and SUMO protein was released from SPINK1 polypeptides by digestion with recombinant His-tag containing SUMOstar protease. The protease and SUMO protein were removed by incubation with Ni-NTA agarose. Finally, SPINK1 was purified by immunoaffinity chromatography and reversed-phase HPLC as previously described [31]. The concentrations of wt SPINK1 and S25TSPINK1 were measured by the TR-IFMA for SPINK1 (see below) and absorbance at $280 \mathrm{~nm}$. Typical yields were $\sim 1 \mathrm{mg}$ SPINK1 per liter of bacterial culture. The SPINK1 fractions were stored at $-20^{\circ} \mathrm{C}$. A SPINK1 stock solution $(73.3 \mathrm{mg} / \mathrm{L})$ was prepared by diluting purified wt SPINK1 with $50 \mathrm{mM}$ Tris- $\mathrm{HCl}, \mathrm{pH} 7.5$, and $150 \mathrm{mM} \mathrm{NaCl}$ (Tris-buffered saline, TBS) containing $50 \mathrm{~g} / \mathrm{L}$ bovine serum albumin (BSA, essentially fatty acid and globulin free $\leq 99 \%$, Sigma Aldrich), and stored at $+4{ }^{\circ} \mathrm{C}$. Calibrators $(0.5-1000 \mu \mathrm{g} / \mathrm{L})$ were diluted freshly from the stock solution with TBS containing $10 \mathrm{mg} /$ L BSA. To prepare the internal standard (IS) stock solution (7.8 $\mathrm{mg} / \mathrm{L})$, purified S24T-SPINK1 was diluted with TBS containing $50 \mathrm{~g} / \mathrm{L} \mathrm{BSA}$ and stored at $+4{ }^{\circ} \mathrm{C}$. IS working solution $(150 \mu \mathrm{g} / \mathrm{L})$ was diluted freshly from the stock solution with TBS containing $10 \mathrm{mg} / \mathrm{L} \mathrm{BSA}$.

\section{Immunocapture of SPINK1}

Antibody (MAb 6E8) recognizing SPINK1 [28] was conjugated to magnetic Protein G Mag Sepharose (called "beads") using the crosslinking protocol provided by the manufacturer (GE Healthcare). With this protocol, the antibody is covalently bound to the beads and it is not eluted with the antigen. 
Table 1 Patient data. Pancreatic amylase, amylase, and C reactive protein (CRP) were analyzed with the modular clinical chemistry analyzer (Hitachi Ltd.) using reagent kits from Roche Diagnostics $\mathrm{BmbH}$

\begin{tabular}{lllll}
\hline Patient group & Suspected AP & RCC & Benign urological conditions & Confirmed SPINK1 genotype \\
\hline Men/Women, $n$ & $24 / 8$ & $18 / 14$ & $15 / 16$ & $23 / 11$ \\
Median age, years (range) & $51(25-86)$ & $62(43-87)$ & $55(26-79)$ & $52(20-86)$ \\
Median CRP, mg/L (range) & $137(6-414)$ & - & - & $24(5-397)$ \\
Median pancreatic amylase, U/L (range) & $342(8-2746)$ & - & - & - \\
Median amylase, U/L (range) & $366(12-3618)$ & - & - & $616(59-5642)$ \\
AP/other patients & $29 / 3$ & - & - & $6 / 28^{\mathrm{a}}$ \\
Etiology, $n$ biliary/alcoholic/unknown & $9 / 20 / 3$ & - & - & - \\
Genotype, $n$ & & & & $11 / 14 / 3 / 6$ \\
Wt/N34S-heteroz./N34S-homoz./P55S-heteroz. & - & $22 / 14$ & - & - \\
Clear cell/papillary RCC, $n$ & - & - & $19 / 12^{\mathrm{b}}$ & - \\
Hematuria/other, $n$ & & & \\
\hline
\end{tabular}

${ }^{\text {a }}$ Chronic pancreatitis 5; alcoholic pancreatitis 10; biliary pancreatitis 5; other 7; unknown 1

${ }^{\mathrm{b}}$ Nephrolithiasis 5 ; ureterolithiasis 3; pollacisuria 2; cystitis recidivans 1; prostate hyperplasia 1

Magnetic beads were coupled in batches $(500 \mu \mathrm{L}$ of slurry at a time, $1 \mathrm{mg} \mathrm{MAb} / 100 \mu \mathrm{L}$ bead slurry) and the coupled beads were stored at $+4{ }^{\circ} \mathrm{C}$.

To $100 \mu \mathrm{L}$ of serum, QA samples and calibrators $20 \mu \mathrm{L}$ of IS $(150 \mu \mathrm{g} / \mathrm{L})$ was added. The calibrators were forwarded for LC-MS analysis without capturing. SPINK1 in QA and serum samples was captured using $20 \mu \mathrm{L}$ of magnetic anti-SPINK1 bead slurry, i.e., $4 \mu \mathrm{L}$ of beads. The beads were first washed twice with TBS. Then, $100 \mu \mathrm{L}$ of sample with IS was added to the beads and incubated for 15 min with gentle shaking at room temperature (Vortex-Genie 2 with a multiple sample head, Scientific Industries). The beads were washed twice with $2 \mathrm{M}$ urea in TBS and once with TBS. Bound SPINK1 was eluted from the beads by adding $50 \mu \mathrm{L}$ of $0.1 \%$ TFA and incubating for $20 \mathrm{~min}$ with shaking. The supernatant was removed and the elution was repeated. The supernatants were combined and the eluted sample was centrifuged for $1 \mathrm{~min}$ at $1100 \mathrm{~g}$ to remove possible residual magnetic particles.

\section{LC-MS}

The instrumentation consisted of an Agilent 1200 liquid chromatography (Agilent Technologies) and a 4000 QTRAP mass spectrometer (AB Sciex) equipped with a Turbo-V electrospray ion source. We used a Polaris C18-
A column ( $3 \mu \mathrm{m}$ particle size, $50 \times 2 \mathrm{~mm}$ ) with a Polaris C18-A guard column (Agilent Technologies). Elution buffers were $0.1 \%$ formic acid (FA) in water (A) and $0.1 \% \mathrm{FA}$ in methanol (B). After injection of the sample $(20 \mu \mathrm{L})$, the proportion of buffer B was ramped from 20 to $100 \%$ in $3 \mathrm{~min}$ and maintained at $100 \%$ for further $3 \mathrm{~min}$. The proportion of B was then reduced to $20 \%$ in $0.5 \mathrm{~min}$ and the column was equilibrated for further $3.5 \mathrm{~min}$. The flow rate was $300 \mu \mathrm{L} / \mathrm{min}$. The ion source spray voltage was $5500 \mathrm{~V}$ and temperature $500{ }^{\circ} \mathrm{C}$. The gas settings were curtain gas 55 psig, nebulizer gas 50 psig, heater gas 45 psig, and collision gas setting 10 . For detection and quantification, we used pseudo-MRM with the following transitions $(\mathrm{m} / \mathrm{z})$ with $250 \mathrm{~ms}$ dwell time: 1041.4/1041.4 (SPINK1, $z=6$, for quantification), 1249.4/1249.4 (SPINK1, $z=5$, for confirmation), and 1043.5/1043.5 (IS, $z=6$ ), and with dwell time $100 \mathrm{~ms}$ : 1036.7/1036.7 (N34S-SPINK1, $z=6)$ and 1039.5/1039.5 (P55S-SPINK1, $z=6$ ).

\section{Analytical validation of the assay}

The limit of detection (LOD) was based on a signal-to-noise ratio $(\mathrm{S} / \mathrm{N})$ of $3(n=10)$. Linearity was determined by preparing eight calibrators with concentrations of $0.5-1000 \mu \mathrm{g} / \mathrm{L}$ in
Fig. 1 The protein sequence of SPINK1. Protein sequence of wild-type SPINK1 (a). The signal sequence is in gray. N34 and P55 are underlined. The sequence of mutated (S25T) SPINK1 used as internal standard (b). The mutated threonine is bolded
A MKVTGIFLIS ALALLSLSGN TGADSLGREA KCYNELNGCT KIYDPVCGTD GNTY PNECVL CEENRKRQTS ILIQKSGPC

B MKVTGIFLIS ALALLSLSGN TGADTLGREA KCYNELNGCT KIYDPVCGTD GNTYPNECVL CFENRKRQTS ILIQKSGPC 
TBS containing $10 \mathrm{mg} / \mathrm{L}$ BSA. Evaluation of the resulting calibration curves was performed with 12 separately prepared dilutions. The stability of calibrator solutions was studied by preparing six calibrator solutions $(1-500 \mu \mathrm{g} / \mathrm{L})$, which were aliquotted and they were kept either at $-20^{\circ} \mathrm{C}$ or at $+4{ }^{\circ} \mathrm{C}$ for 1 week to 3 months. The stability was estimated by calculating the coefficient of variation (CV\%) of relative peak areas (calibrator peak area / IS peak area). The calibration curves were derived using $1 / \mathrm{x}^{2}$ weighted linear least-squares regression by the quantitation option of the Analyst 1.5 software (AB Sciex). The accuracy (mean relative error, RE\%) and the precision $(\mathrm{CV} \%)$ were calculated. The limit of quantitation (LOQ) and linear range were defined as the lowest concentration and range, respectively, which could be measured with an inaccuracy and imprecision $<20 \%$. Intra- and inter-assay variation were calculated from 14 replicates in one and 15 consecutive assays, respectively. Recovery of added SPINK1 was calculated from three samples supplemented with $0 \mu \mathrm{g} / \mathrm{L}$, $20 \mu \mathrm{g} / \mathrm{L}$, or $100 \mu \mathrm{g} / \mathrm{mL}$ of recombinant SPINK1. The matrix effect was calculated from three immunopurified samples supplemented with 0,10 , or $300 \mu \mathrm{g} / \mathrm{L}$ of purified SPINK1 and $25 \mu \mathrm{g} / \mathrm{L}$ of IS, respectively. To avoid carry-over, we recommend sampler needle and injector valve washing procedures. The effect of potential interfering substances is described in the results.

\section{Time-resolved immunofluometric assay}

The time-resolved immunofluorometric assay (TR-IFMA) for SPINK1 was performed as previously described [28, 29]. Briefly, MAbs F62-6E8 and F62-11B3 were used as capture and tracer antibodies, respectively. F62-11B3 was labeled with europium (Eu) using isothiocyanatophenyldiethylenetriamineN1,N2,N3,N4-tetraacetate chelated with $\mathrm{Eu}(\mathrm{III})$ [32]. Microtitration wells were coated with F62-6E8 and $25 \mu \mathrm{L}$ of calibrators (from 0.5 to $90 \mu \mathrm{g} / \mathrm{L}$ ) and samples together with $200 \mu \mathrm{L}$ DELFIA ${ }^{\circledR}$ assay buffer (PerkinElmer) were added to the wells and incubated at room temperature for $1 \mathrm{~h}$. All incubations were performed under constant shaking (DELFIA ${ }^{\circledR}$ Plateshake, PerkinElmer). The wells were washed twice with DELFIA ${ }^{\circledR}$ Wash solution (PerkinElmer) and $50 \mathrm{ng}$ of Eulabeled tracer in $200 \mu \mathrm{L}$ of assay buffer was added per well and incubated for $30 \mathrm{~min}$. After four washes, DELFIA ${ }^{\circledR}$ Enhancement solution (PerkinElmer) was added with a Delfia ${ }^{\circledR}$ plate dispenser (PerkinElmer) and the fluorescence measured for $1 \mathrm{~s}$ per well using a Victor2 1420 Multilabel HTS Counter (PerkinElmer).

\section{Statistical methods}

The coefficient of variation, Student's $t$ test, and BlandAltman plot were calculated with Analyse-it for Microsoft ${ }^{\circledR}$ Excel 2003 (version 2.04, http://www. analyse-it.com/). Other analyses were performed with $\mathrm{R}$ (version 2.13.0) package "psych" (version 1.2.8, http:// personality-project.org/r/), "epicalc" (version 2.15.1.0, http://CRAN.R-project.org/), and with "MethComp" (version 1.22, http://bendixcarstensen.com/MethComp/).

\section{Results}

\section{Validation of the LC-MS assay for SPINK1}

SPINK1 and the IS eluted at a retention time of $3.3 \mathrm{~min}$ (Fig. 2). The LC-MS assay for SPINK1 was linear over the concentration range of $0.5-1000 \mu \mathrm{g} / \mathrm{L}$, but as working calibrators we routinely used $1-500 \mu \mathrm{g} / \mathrm{L}$ (Fig. 3). Calibrators at concentrations of $2-500$ and $5-500 \mu \mathrm{g} / \mathrm{L}$ were stable for 2 months at $-20{ }^{\circ} \mathrm{C}$ and at $+4{ }^{\circ} \mathrm{C}$, respectively. The LOD was $0.15 \mu \mathrm{g} / \mathrm{L}$ and the LOQ was $0.5 \mu \mathrm{g} / \mathrm{L}$. The intra-assay CVs were 6.4 and $4.2 \%$ and the inter-assay CVs 17.7 and $16.4 \%$ at concentrations of 11 and $75 \mu \mathrm{g} / \mathrm{L}$, respectively. The recovery of added SPINK1 $(20$ and $100 \mu \mathrm{g} / \mathrm{L})$ in serum samples containing $11.2,50.3$, and $273 \mu \mathrm{g} / \mathrm{L}$ endogenous SPINK1 was $87-$ $100 \%$. When spiked into immunopurified serum, we observed ionization suppression to 88 and $58 \%$ for 10 and $300 \mu \mathrm{g} / \mathrm{L}$ of SPINK1, respectively, and to $77 \%$ for the IS $(25 \mu \mathrm{g} / \mathrm{L})$. As calculated from the peak areas of samples spiked with SPINK1 $(10$ and $300 \mu \mathrm{g} / \mathrm{L})$ or IS $(25 \mu \mathrm{g} / \mathrm{L})$ either pre- or post-immunocapture, the recovery of the immunopurification was 91 and $129 \%$ for SPINK1, respectively and $94 \%$ for the IS. When measured by TRIFMA, the recovery for SPINK1 was $100 \%$.

\section{Detection of SPINK1 variants by LC-MS}

The $m / z$ difference of the sextuply charged ions of $w t$ SPINK $1(6240 \mathrm{Da}), \mathrm{N} 34 \mathrm{~S}-(6214 \mathrm{Da})$, P55S$(6231 \mathrm{Da})$, and S25T-SPINK1 (6255 Da) used as IS allows mass spectrometric analysis of each SPINK1 form separately. The mean SPINK1 concentration in serum samples from AP patients with confirmed N34SSPINK1 $(n=17)$ or P55S-SPINK1 $(n=6)$ variant was $143 \mu \mathrm{g} / \mathrm{L}(95 \% \mathrm{CI} 49.8-164 \mu \mathrm{g} / \mathrm{L})$ as measured by the TR-IFMA. The mean wt SPINK1 concentration by LCMS assay was $67.2 \mu \mathrm{g} / \mathrm{L}(22.1-81.7 \mu \mathrm{g} / \mathrm{L})$ and the mean total SPINK1 concentration, i.e., the sum of wt SPINK1, and N34S-SPINK1 or P55S-SPINK1 was $107 \mu \mathrm{g} / \mathrm{L}$ $(49.8-163.4 \mu \mathrm{g} / \mathrm{L})$.

To estimate the ability of our LC-MS assay to distinguish between homozygous and heterozygous SPINK1 variation carriers, we compared the peak areas of the samples from individuals with confirmed SPINK1 genotype [21]. The peak area of wt SPINK1 and N34S- 


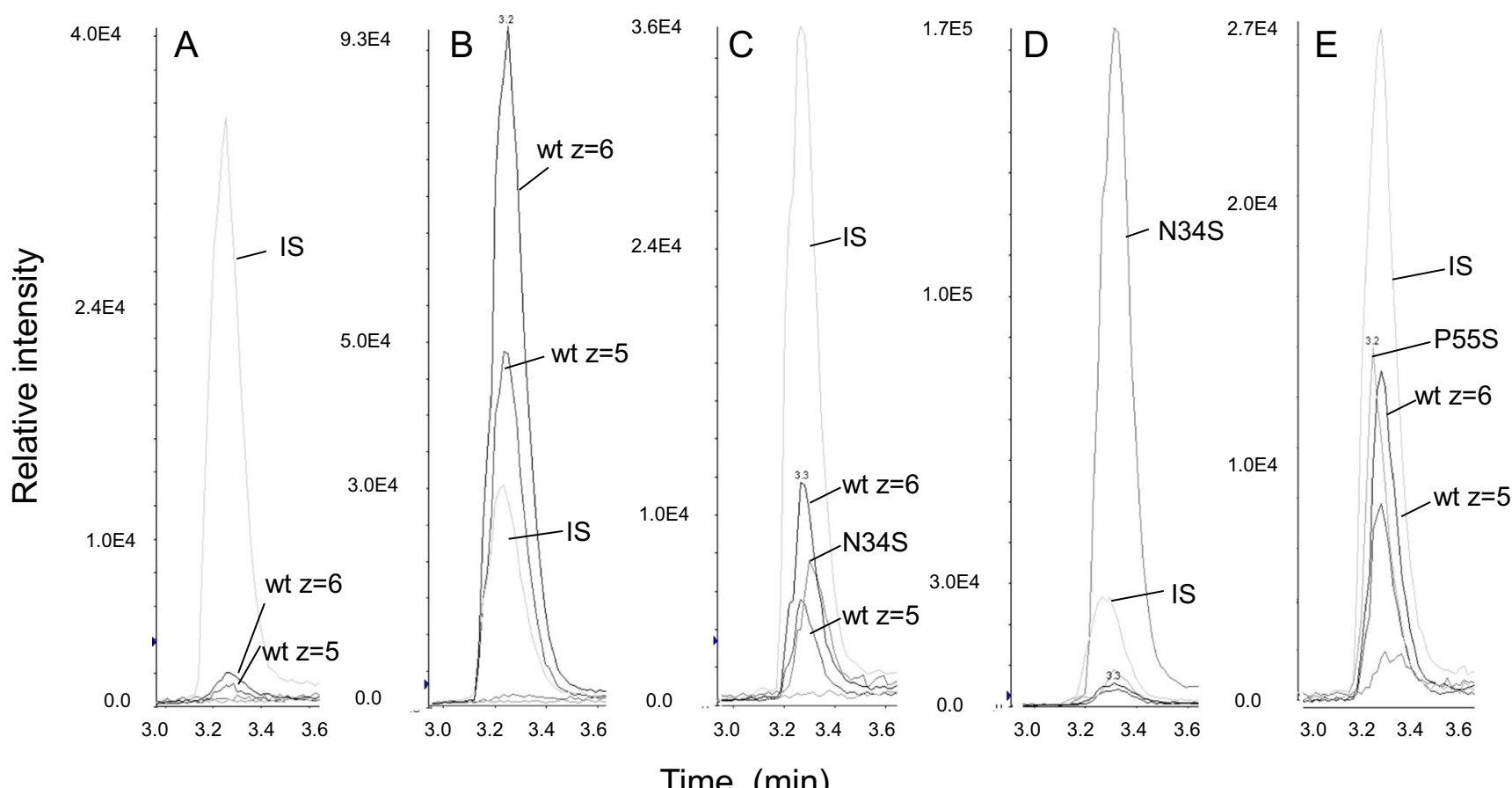

Fig. 2 LC-MS chromatograms. LC-MS chromatograms of a $5 \mu \mathrm{g} / \mathrm{L}$ recombinant SPINK1 calibrator (a) and samples from confirmed wild-type (b), heterozygous N34S- (c), homozygous N34S- (d), and heterozygous P55S-SPINK1 (e) individuals. The lines from black to the lightest gray represent wt SPINK1 $\mathrm{m} / \mathrm{z}, 1041.4(z=6)$ and $\mathrm{m} / \mathrm{z} 1249.4(z=5), \mathrm{N} 34 \mathrm{~S}$ SPINK1 $(m / z, 1036.7, z=6)$, P55S-SPINK1 $(m / z, 1039.5, z=6)$, and IS $(\mathrm{m} / \mathrm{z} 1043.5, z=6)$, respectively. $Y$-axis shows the peak height (cps) and $x$ axis the chromatographic elution time (min)
SPINK1 is approximately equal in samples from heterozygous subjects (Fig. 2c). However, in the chromatogram of a homozygous N34S-SPINK1 carrier's sample (Fig. 2d), only a minor if any signal of wt SPINK1 is seen. In order to numerically represent the apparent genotype based on LC-MS, we calculated a zygosity score as the ratio of wt SPINK1 to total SPINK1, i.e., wt SPINK1/ (mutated SPINK1 + wt SPINK1), from the respective peak areas of the samples. In samples from confirmed homozygous N34S-SPINK1 carriers $(n=3)$, confirmed heterozygous N34S-SPINK1 carriers $(n=13)$, and control subjects with confirmed wt SPINK1 $(n=15)$, the median
Fig. 3 Calibration curve of the IC-LC-MS analysis SPINK1 calibration curve showing the linear range of the assay

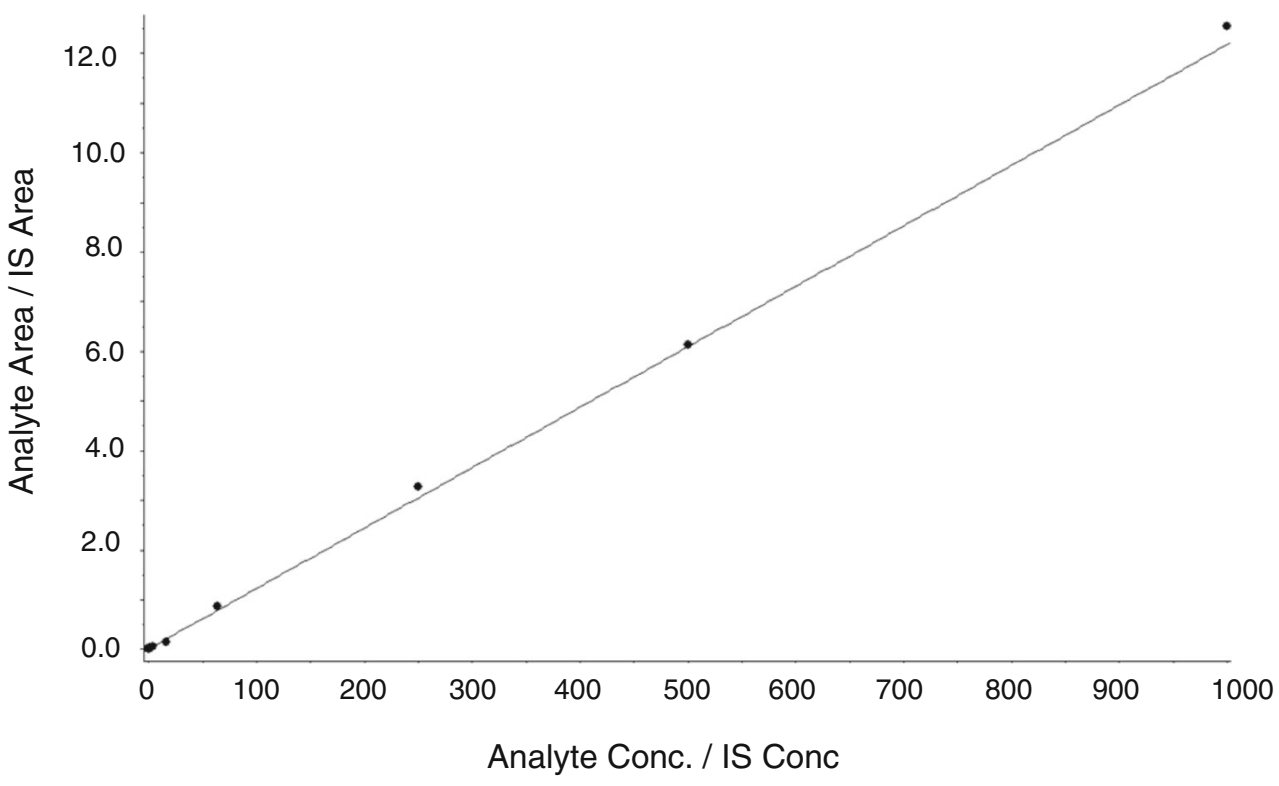


zygosity score was 0.05 (range 0.04-0.07), 0.55 (95\% CI $0.43-0.61$ ), and 1.00 (95\% CI $0.98-1.01)$, respectively (Fig. 4). The result of one heterozygous N34S carrier (1.03) was excluded as an outlier after repeated DNA and LC-MS analyses. Patients with confirmed P55SSPINK1 (Fig. 2e) variant were all heterozygous $(n=6)$ with a median zygosity score of 0.56 (range $0.53-0.76$ ). Variability of the zygosity score was studied with repeated assays $(n=5-7)$ of each different type of patients. The coefficient of variation in the zygosity score was the lowest $(0.8-5.0 \%)$ for the wild-type samples (range $0.88-1.02), 4.9-21.5 \%$ for heterozygous N34S or P55S samples (range 0.31-0.76), and the highest (46.1-73.5\%) for homozygous N34S samples (range 0.03-0.29).

Therefore, we suggest that a zygosity score $>0.8,0.3-0.8$, and $<0.3$ indicates a wt, heterozygous, and homozygous genotype, respectively.

\section{The effect of interfering substances}

To study the effects of potential interfering factors to our assay, we selected among our patient samples (stripped of identifiers) those with elevated rheumatoid factor (449 and $986 \mathrm{IU} / \mathrm{mL}$ ), lipemia (L-index 76 and 347 by Roche Modular clinical chemistry analyzer), monoclonal gammopathy with IgG6 (56 g/L), IgM1 (21 and $29 \mathrm{~g} /$ L), IgA2 (45 g/L) (by capillary electrophoresis and agarose gel electrophoresis followed by immunofixation), and one sample with interference in our THS assay (21.5 mU/L with Abbott Architect immunoanalyzer). After this sample was treated with heterophilic blocking

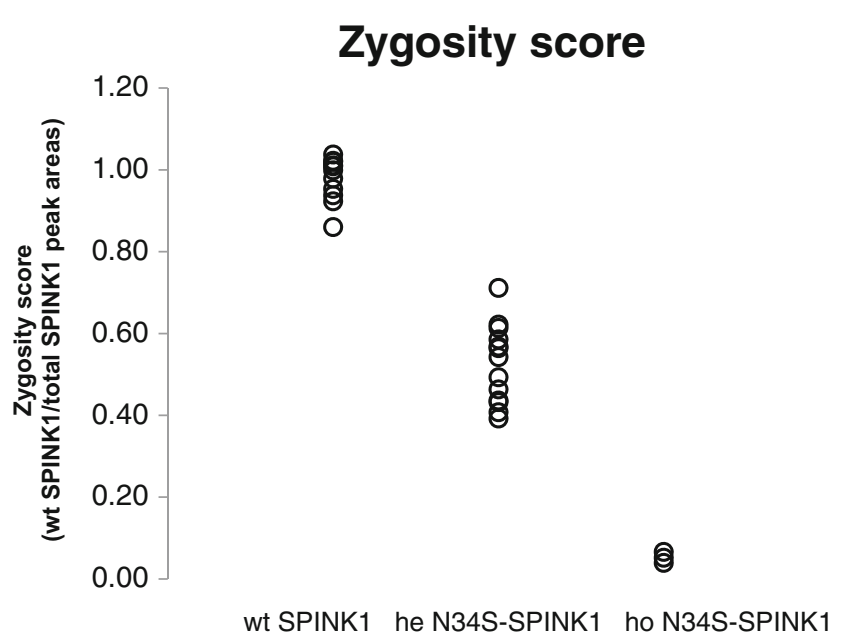

Fig. 4 Calculated zygosity scores according to confirmed genotype. Calculated zygosity scores (wt SPINK1/total SPINK1 peak areas) are plotted separately for samples from confirmed wt individuals (wt SPINK1), heterozygous N34S-SPINK1 carriers (he N34S-SPINK1), and homozygous N34S-SPINK1 carriers (ho N34S-SPINK1). The result (1.03) of one heterozygous individual is deleted as an outlier tube (HBT from Scantibodies Laboratory, Inc., Santee, CA) and reanalyzed, the TSH result was $1.5 \mathrm{mU} / \mathrm{L}$. Therefore, the interfering factor was likely to be heterophilic antibodies.

Serum samples from pancreatitis patients with confirmed wild-type or heterozygous N34S genotype (by DNA analysis) were diluted 1:2 with interfering serum samples. Interfering substances were found to cause decreased SPINK1 results (mean $74 \%$, range $54-115 \%$ of expected concentration, Table 2). On the other hand, the interference was sample dependent, i.e., the change in expected concentration of two different patient samples by one interfering sample varied between 54-115\% (rheumatoid factor) and 55-101\% (monoclonal IgG6).

\section{Comparison of TR-IFMA and LC-MS assay for SPINK1}

In addition to the patients with previously identified SPINK1 variants, we analyzed 95 serum samples from patients with RCC, benign urological conditions, and suspected for AP. In AP patients, the mean serum concentration of SPINK1 was $243 \mu \mathrm{g} / \mathrm{L}(95 \%$ CI $178-307 \mu \mathrm{g} / \mathrm{L})$ by the TR-IFMA and $274 \mu \mathrm{g} / \mathrm{L}(95 \%$ CI $181-368 \mu \mathrm{g} / \mathrm{L}$ ) by the LC-MS assay. In RCC patients, the concentrations were $32.2 \mu \mathrm{g} / \mathrm{L}(95 \%$ CI $18.8-45.6 \mu \mathrm{g} / \mathrm{L})$ and $45.4 \mu \mathrm{g} / \mathrm{L}$ (95\% CI $16.9-73.9 \mu \mathrm{g} / \mathrm{L})$ and in benign controls $11.3 \mu \mathrm{g} / \mathrm{L}(95 \%$ CI $9.7-12.9 \mu \mathrm{g} / \mathrm{L})$ and $12.6 \mu \mathrm{g} / \mathrm{L}(95 \%$ CI $10.7-14.5 \mu \mathrm{g} / \mathrm{L})$, respectively. There were no significant differences between SPINK1 concentrations as measured by the TR-IFMA and the LC-MS assay except in samples from benign controls $(p<0.05)$ (Fig. 5). The results by TR-IFMA (x) and LC-MS (y) correlated according to an equation $y=1.17 \mathrm{x}-13.6$ (Deming regression, Sy $\mid x=0.498, R^{2}=0.94, n=95$ ).

We observed by IC-LC-MS an apparent N34SSPINK1 variant in 4 of $32(12.5 \%)$ samples from suspected AP and in 1 of 32 (3.1\%) samples from RCC patients. The genotype of these patients has not been confirmed by DNA analysis. The zygosity scores were $0.58,0.55,0.35,0.54$, and 0.05 . This suggests that one of the patients is a homozygous and four are heterozygous N34S-SPINK1 carriers. We did not see a P55SSPINK1 variant in patient samples that were not previously genotyped.

\section{Discussion}

We have developed an immunocapture-LC-MS assay for simultaneous detection and quantification of serum $\mathrm{wt}$ SPINK1, and N34S-SPINK1 and P55S-SPINK1 variants. The assay employs a SPINK1 antibody coupled to magnetic beads, recombinant SPINK1 calibrator, and a 
Table 2 The effect of interfering substances to SPINK1 concentration as measured by immunocapture-LC-MS. Serum samples were diluted 1:2 with samples containing the denoted amount of interfering substance. Theoretical SPINK1 concentration was calculated as the mean of SPINK1

concentration measured in the interfering sample and the patient sample

\begin{tabular}{|c|c|c|c|c|c|}
\hline \multirow[b]{2}{*}{ Interfering factor } & \multicolumn{3}{|c|}{ Measured SPINK1 $(\mu \mathrm{g} / \mathrm{L})$} & \multicolumn{2}{|c|}{$\begin{array}{l}\text { Theoretical } \\
\text { concentration }\end{array}$} \\
\hline & Interf. sample & Patient sample & Interf:Patient 1:1 & $\mu \mathrm{g} / \mathrm{L}$ & $\%$ \\
\hline \multirow[t]{2}{*}{ Rheumatoid factor $449 \mathrm{IU} / \mathrm{mL}$} & 90 & 518 & 164 & 304 & 54 \\
\hline & 100 & 45 & 83 & 72 & 115 \\
\hline \multirow[t]{2}{*}{ Rheumatoid factor $986 \mathrm{IU} / \mathrm{mL}$} & 27 & 518 & 156 & 272 & 57 \\
\hline & 21 & 45 & 23 & 33 & 70 \\
\hline \multirow[t]{2}{*}{ Lipemic index 76} & 80 & 518 & 224 & 299 & 75 \\
\hline & 56 & 45 & 36 & 50 & 71 \\
\hline \multirow[t]{2}{*}{ Lipemic index 347} & 36 & 518 & 197 & 277 & 71 \\
\hline & 26 & 45 & 20 & 35 & 57 \\
\hline \multirow[t]{2}{*}{ Monoclonal IgG6 $56 \mathrm{~g} / \mathrm{L}$} & 53 & 518 & 158 & 285 & 55 \\
\hline & 46 & 45 & 46 & 46 & 101 \\
\hline Monoclonal IgM1 $21 \mathrm{~g} / \mathrm{L}$ & 137 & 518 & 230 & 328 & 70 \\
\hline Monoclonal IgM1 $29 \mathrm{~g} / \mathrm{L}$ & 56 & 45 & 33 & 51 & 64 \\
\hline \multirow[t]{2}{*}{ Monoclonal IgA2 $45 \mathrm{~g} / \mathrm{L}$} & 70 & 518 & 202 & 294 & 69 \\
\hline & 77 & 45 & 68 & 61 & 111 \\
\hline \multirow[t]{2}{*}{ Heterophilic interference } & 14 & 256 & 93 & 135 & 69 \\
\hline & 36 & 45 & 29 & 40 & 71 \\
\hline Mean & & & & & 74 \\
\hline Min & & & & & 54 \\
\hline Max & & & & & 115 \\
\hline
\end{tabular}

recombinant S25T-SPINK1 internal standard. The assay range is wide $(0.5-1000 \mu \mathrm{g} / \mathrm{L})$. The sensitivity $(0.5 \mu \mathrm{g} / \mathrm{L})$ is comparable to that of a previously described TR-IFMA $(0.13 \mu \mathrm{g} / \mathrm{L})$ and ELISA $(0.8 \mu \mathrm{g} / \mathrm{L})$ for SPINK1 [28] and clearly better than that of a former commercial radioimmunoassay $(7 \mu \mathrm{g} / \mathrm{L})$. The high sensitivity and the wide assay range of our new assay are advantageous both in clinical and research settings.

The present assay is based on pseudo-MRM employing low collision energy to reduce possible isobaric interferences.

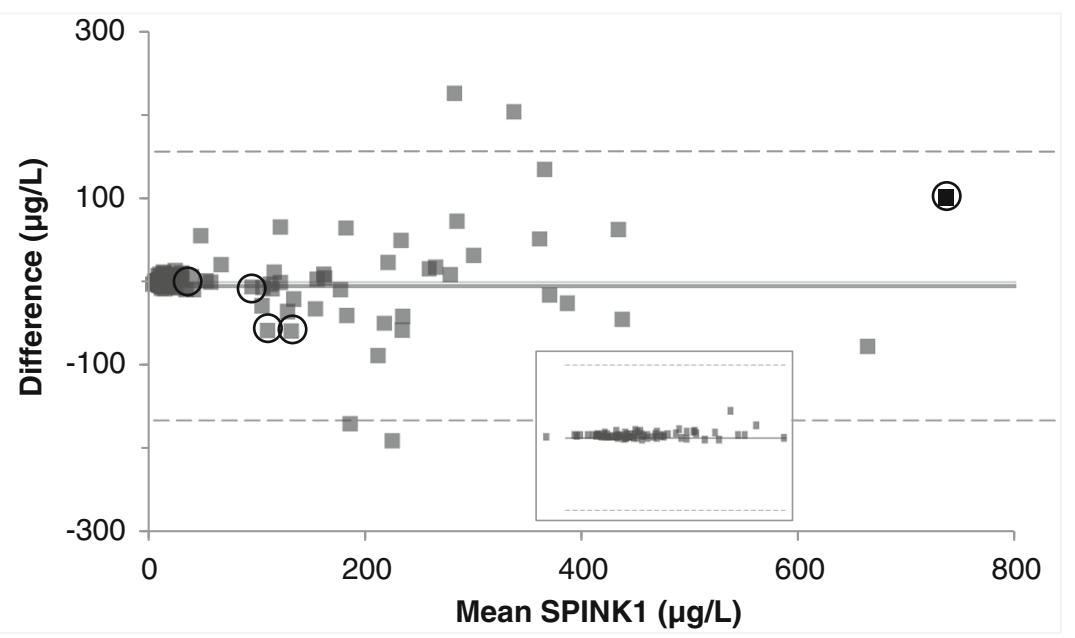

Fig. 5 Comparison of TR-IFMA and LC-MS results. Serum samples from patients suspected for AP $(n=32)$, with RCC $(n=32)$ and with benign urological conditions $(n=31)$ were measured by IC-LC-MS and TR-IFMA. In the Bland-Altman plot, the absolute difference between the two methods is plotted against their mean. Gray line shows identity and dotted line $95 \%$ limits of acceptance. The insert shows comparison of
SPINK1 concentrations 4.7-96.6 $\mu \mathrm{g} / \mathrm{L}$ with a $\log$ scale $x$-axis. One sample from an AP patient with a SPINK1 concentration $713 \mu \mathrm{g} / \mathrm{L}$ by the TRIFMA and $1440 \mu \mathrm{g} / \mathrm{L}$ by the IC-LC-MS assay is not shown. Samples with newly found apparent heterozygous N34S-SPINK1 variants are circled 
Especially at low concentrations, the mean SPINK1 concentrations were slightly higher by our IC-LC-MS than immunoassay suggesting a minor bias. In general, multiple reaction monitoring (MRM)-based assays are more specific and sensitive. However, an MRM assay of 6240 Da SPINK1 was not possible without an extra step of enzymatic digestion. We found that common known interfering factors may decrease the measured SPINK1 concentration. Thus, it should be kept in mind that immunocapture in non-diluted serum may be prone to interference, which is also the case with conventional immunoassays. The newly developed assay for total serum SPINK1 and the previously described TR-IFMA for SPINK1 [28] show relatively good correlation. Therefore, we consider the present straightforward pseudo-MRM assay suitable for quantification of SPINK1 and especially for detection of SPINK1 variants.

In LC-MS analysis, an ideal IS corrects for the recovery during sample preparation and chromatography and for the matrix effects during ionization. The most common practice is to employ a stable isotopically labeled (SIL) IS especially for small molecules. The use of an analog peptide is an alternative for SIL in peptide assays. A non-isotopic mutated IS peptide, in which leucine was replaced with alanine, has been compared to a SIL peptide for analysis of NAD(P)H:quinone oxidoreductase 1 (NQO1) [33]. NQO1 was quantified in extracts of cells and tumor tissues and there was no significant differences in the results between these two ISs. We used mutated recombinant S25T-SPINK1 as an internal standard. Such a mutation has not been described in endogenous SPINK1. Replacement of serine with threonine in SPINK1 was not expected to alter the chemical properties of the peptide. Indeed, the chromatographic and ionization properties of wt SPINK1 and S25T-SPINK1 were found to be similar. The acceptable correlation of our IC-LC-MS assay with TR-IFMA for SPINK1 suggests that S25T-SPINK1 is suitable for use as an IS.

Thus far, SPINK1 has been quantified by immunoassays often with high sensitivity. The selectivity depends on the antibodies employed, but immunoassays may lack specificity $[34,35]$. A unique property of MS-based methods compared to immunoassays is the ability to detect different isoforms [36] and posttranslational modifications [31, 37]. For example, four different forms of Ras protein have been detected and quantified by LC-MS in tumor tissue, premalignant pancreatic cyst fluids, and cell lines [36]. However, only the relative abundance of these isoforms, not the absolute quantity, could be determined. Mass spectrometric detection of wt SPINK1, N34S-, and P55S-SPINK1 has been demonstrated earlier [31], but the method was not quantitative. We show that by using S25T-mutated SPINK1 as an IS, it is possible to quantify wt SPINK1, N34S-, and P55S-SPINK1 in serum samples. As expected, the concentration of wt SPINK1 by LC-MS was much lower than total SPINK1 concentration by TR-IFMA in serum samples from heterozygotes, but the total SPINK1 concentration (wt SPINK1 + mutated SPINK1) by LC-MS was in line with TR-IFMA results. This finding supports that the quantitative performances of S25T-, N34S-, P55SSPINK1, and wt SPINK1 in our pseudo-MRM assay are similar.

We found that the IC-LC-MS analysis can be used to determine the apparent zygosity of the variants N34S- or P55SSPINK1 with the help of zygosity score. The score can be calculated based on the ratio of the peak areas of wt- and total SPINK1. By this means, the zygosity score of all confirmed wt subjects $(n=11)$, homozygous N34S carriers $(n=3)$, and 13 of 14 heterozygous subjects were in accordance with the DNA data. According to the zygosity score, one subject appeared to have repeatedly a wt phenotype (score 1.03) despite the heterozygous genotype. There are several possible explanations for this discrepancy. First, it is possible that both alleles are not always expressed equally at the protein level. The proportion of N34S-SPINK1 has been found to be higher than that of wt SPINK1 in urine $(n=12)$ and sera $(n=2)$ of heterozygous pancreatitis patients as shown earlier in a limited study [31]. On the other hand, this is not supported by our present data. Secondly, it is possible that yet another mutation results in the same $m / z$ as that for wt SPINK1. Thirdly, a human mistake in sample tagging is possible. The number of patients ( $n=34)$ with confirmed SPINK1 variants in our study is limited. Therefore, further studies comparing the zygosity score and DNA analysis are warranted. The current results are, however, promising, and may provide a new DNA-free detection of known variants of SPINK1.

The presence of N34S-SPINK1 variant, but not the zygosity, has been shown to associate with increased risk of developing CP after a sentinel AP incident [16, 21, 38-40]. However, the variant does not increase the risk of the first incident. The occurrence of the variant in Finnish general population is $2.5 \%[16,21]$ and in patients with AP and CP, it is $7.8 \%$ [21] and $12 \%$ [16], respectively. Thus, the occurrence of N34S-SPINK1 in samples from AP (13\%) and benign urological disease $(1.6 \%)$ patients whose genotype has not been confirmed by DNA analysis is in line with earlier reports. Sentinel AP patients carrying the N34S-SPINK1 variant have been shown to be about 19 times more prone to develop recurrent attacks [20]. Therefore, identification of N34S-SPINK1 carriers with an initial attack of AP could be used to prevent recurrent attacks or progression of AP to CP. Furthermore, our new assay enables identification of SPINK1 variants also in archival samples when DNA is not available.

In conclusion, we have developed an immunocapture-LCMS assay for serum SPINK1 and compared it with an immunoassay. The recombinant mutated SPINK1 used as an internal standard offers a cost-effective alternative to stable isotope-labeled peptides. In addition to wt SPINK1, our new assay facilitates detection and quantification of N34S- and 
P55S-SPINK1 variants known to associate with pancreatitis. Moreover, by calculating a wt-to-total SPINK1 ratio, it is possible to determine the apparent zygosity of the variant without DNA analysis. Therefore, this assay could be used for variant screening and may help identifying patients with increased risk for $\mathrm{CP}$ due to SPINK1 variants.

Acknowledgements The authors thank Ms. Maarit Leinimaa and Ms. Marianne Niemelä for expert technical assistance. This work was supported by the grants from the Academy of Finland, Finska läkaresällskapet, Sigrid Jusélius Foundation, Medical Faculty of the University of Helsinki, Biomedicum Helsinki Foundation, and Timo Lehtonen Urology Fund.

Compliance with ethical standards S. Ravela and L. Valmu work currently at ThermoFisher Scientific, but S. Ravela was a University of Helsinki employee and L. Valmu was a Finnish Red Cross employee at the time of the study. ThermoFisher Scientific has not participated nor supported this study. The authors have no other conflict of interests.

The study was approved by the ethical committee of Helsinki University Central Hospital, Finland. Informed consent was obtained from all individuals.

\section{References}

1. Pubols MH, Bartelt DC, Greene LJ. Trypsin inhibitor from human pancreas and pancreatic juice. J Biol Chem. 1974:2235-42.

2. Rinderknecht H. Activation of pancreatic zymogens. Normal activation, premature intrapancreatic activation, protective mechanisms against inappropriate activation. Dig Dis Sci. 1986;31:314-21.

3. Lukkonen A, Lintula S, von Boguslawski K, Carpen O, Ljungberg $\mathrm{B}$, Landberg $\mathrm{G}$, et al. Tumor-associated trypsin inhibitor in normal and malignant renal tissue and in serum of renal-cell carcinoma patients. Int J Cancer. 1999:486-90.

4. Paju A, Hotakainen K, Cao Y, Laurila T, Gadaleanu V, Hemminki A, et al. Increased expression of tumor-associated trypsin inhibitor, TATI, in prostate cancer and in androgen-independent 22Rv1 cells. Eur Urol. 2007;

5. Freeman TC, Playford RJ, Quinn C, Beardshall K, Poulter L, Young J, et al. Pancreatic secretory trypsin inhibitor in gastrointestinal mucosa and gastric juice. Gut. 1990:1318-23.

6. Itkonen O, Stenman UH. TATI as a biomarker. Clin Chim Acta. 2014:260-9.

7. Stenman UH, Huhtala ML, Koistinen R, Seppala M. Immunochemical demonstration of an ovarian cancer-associated urinary peptide. Int J Cancer. 1982:53-7.

8. Hedstrom J, Sainio V, Kemppainen E, Puolakkainen P, Haapiainen R, Kivilaakso E, et al. Urine trypsinogen-2 as marker of acute pancreatitis. Clin Chem. 1996:685-90.

9. Kylanpaa-Back ML, Kemppainen E, Puolakkainen P, Hedstrom J, Haapiainen R, Korvuo A, et al. Comparison of urine trypsinogen-2 test strip with serum lipase in the diagnosis of acute pancreatitis. Hepato-Gastroenterology. 2002:1130-4.

10. Eddeland A, Ohlsson KA. Radioimmunoassay for measurement of human pancreatic secretory trypsin inhibitor in different body fluids. Hoppe Seylers Z Physiol Chem. 1978:671-5.

11. Satake K, Inui A, Sogabe T, Yoshii Y, Nakata B, Tanaka H, et al. The measurement of serum immunoreactive pancreatic secretory trypsin inhibitor in gastrointestinal cancer and pancreatic disease. Int J Pancreatol. 1988:323-31.
12. Lasson A, Borgstrom A, Ohlsson K. Serum levels of immunoreactive PSTI in acute abdominal disorders, with special reference to a possible extrapancreatic PSTI production. Clin Chim Acta. 1986: $37-46$.

13. Chen JM, Mercier B, Audrezet MP, Ferec C. Mutational analysis of the human pancreatic secretory trypsin inhibitor (PSTI) gene in hereditary and sporadic chronic pancreatitis. J Med Genet. 2000: 67-9.

14. Witt H, Luck W, Hennies HC, Classen M, Kage A, Lass U, et al. Mutations in the gene encoding the serine protease inhibitor, Kazal type 1 are associated with chronic pancreatitis. Nat Genet. 2000: 213-6.

15. Pfutzer RH, Barmada MM, Brunskill AP, Finch R, Hart PS, Neoptolemos J, et al. SPINK1/PSTI polymorphisms act as disease modifiers in familial and idiopathic chronic pancreatitis. Gastroenterology. 2000:615-23.

16. Lempinen M, Paju A, Kemppainen E, Smura T, Kylanpaa ML, Nevanlinna H, et al. Mutations N34S and P55S of the SPINK1 gene in patients with chronic pancreatitis or pancreatic cancer and in healthy subjects: a report from Finland. Scand J Gastroenterol. 2005;40:225-30.

17. Schneider A. Serine protease inhibitor kazal type 1 mutations and pancreatitis. Clin Lab Med. 2005;25:61-78.

18. Gomez-Lira M, Bonamini D, Castellani C, Unis L, Cavallini G, Assael BM, et al. Mutations in the SPINK1 gene in idiopathic pancreatitis Italian patients. Eur J Hum Genet. 2003;11:543-6.

19. Threadgold J, Greenhalf W, Ellis I, Howes N, Lerch MM, Simon P, et al. The N34S mutation of SPINK1 (PSTI) is associated with a familial pattern of idiopathic chronic pancreatitis but does not cause the disease. Gut. 2002;50:675-81.

20. Aoun E, Chang CC, Greer JB, Papachristou GI, Barmada MM, Whitcomb DC. Pathways to injury in chronic pancreatitis: decoding the role of the high-risk SPINK1 N34S haplotype using meta-analysis. PLoS One. 2008:e2003.

21. Tukiainen E, Kylanpaa ML, Kemppainen E, Nevanlinna H, Paju A, Repo H, et al. Pancreatic secretory trypsin inhibitor (SPINK1) gene mutations in patients with acute pancreatitis. Pancreas. 2005;30: 239-42.

22. O'Reilly DA, Witt H, Rahman SH, Schulz HU, Sargen K, Kage A, et al. The SPINK1 N34S variant is associated with acute pancreatitis. Eur J Gastroenterol Hepatol. 2008:726-31.

23. Kuwata K, Hirota M, Shimizu H, Nakae M, Nishihara S, Takimoto A, et al. Functional analysis of recombinant pancreatic secretory trypsin inhibitor protein with amino-acid substitution. J Gastroenterol. 2002:928-34.

24. Kiraly O, Wartmann T, Sahin-Toth M. Missense mutations in pancreatic secretory trypsin inhibitor (SPINK1) cause intracellular retention and degradation. Gut. 2007:1433-8.

25. Boulling A, Le Marechal C, Trouve P, Raguenes O, Chen JM, Ferec C. Functional analysis of pancreatitis-associated missense mutations in the pancreatic secretory trypsin inhibitor (SPINK1) gene. Eur J Hum Genet. 2007:936-42.

26. Bohe H, Bohe M, Jonsson P, Lindstrom C, Ohlsson K. Quantification of pancreatic secretory trypsin inhibitor in colonic carcinoma and normal adjacent colonic mucosa. J Clin Pathol. 1992:1066-9.

27. Kurobe M, Kato A, Takei Y, Hayashi K. Fluorometric enzyme immunoassay of basic fibroblast growth factor with monoclonal antibodies. Clin Chem. 1992:2121-3.

28. Janeiro E, Guimarães J, Stenman U, Catarino M, Itkonen O. Validation and comparison of tumor-associated trypsin inhibitor (TATI) immunoassays. Clin Chim Acta. 2012:1244-8.

29. Osman S, Turpeinen U, Itkonen O, Stenman UH. Optimization of a time-resolved immunofluorometric assay for tumor-associated trypsin inhibitor (TATI) using the streptavidin-biotin system. J Immunol Methods. 1993:97-106. 
30. Banks PA, Bollen TL, Dervenis C, Gooszen HG, Johnson CD, Sarr $\mathrm{MG}$, et al. Acute pancreatitis classification working group. Classification of acute pancreatitis - 2012: revision of the Atlanta classification and definitions by international consensus. Gut. 2013: $102-11$.

31. Valmu L, Paju A, Lempinen M, Kemppainen E, Stenman UH. Application of proteomic technology in identifying pancreatic secretory trypsin inhibitor variants in urine of patients with pancreatitis. Clin Chem. 2006;52:73-81.

32. Hemmila I, Dakubu S, Mukkala VM, Siitari H, Lovgren T. Europium as a label in time-resolved immunofluorometric assays. Anal Biochem. 1984:335-43.

33. Tang Z, Wu M, Li Y, Zheng X, Liu H, Cheng X, et al. Absolute quantification of $\mathrm{NAD}(\mathrm{P}) \mathrm{H}$ :quinone oxidoreductase 1 in human tumor cell lines and tissues by liquid chromatography-mass spectrometry/mass spectrometry using both isotopic and nonisotopic internal standards. Anal Chim Acta. 2013:59-67.

34. Chen Z, Caulfield MP, McPhaul MJ, Reitz RE, Taylor SW, Clarke NJ. Quantitative insulin analysis using liquid chromatographytandem mass spectrometry in a high-throughput clinical laboratory. Clin Chem. 2013:1349-56.
35. Jeffery J, Mackenzie F, Beckett G, Perry L, Ayling R. Norethisterone interference in testosterone assays. Ann Clin Biochem. 2013;

36. Wang Q, Chaerkady R, Wu J, Hwang HJ, Papadopoulos N, Kopelovich L, et al. Mutant proteins as cancer-specific biomarkers. Proc Natl Acad Sci U S A. 2011:2444-9.

37. Gerber SA, Rush J, Stemman O, Kirschner MW, Gygi SP. Absolute quantification of proteins and phosphoproteins from cell lysates by tandem MS. Proc Natl Acad Sci U S A. 2003:6940-5.

38. Truninger K, Witt H, Kock J, Kage A, Seifert B, Ammann RW, et al. Mutations of the serine protease inhibitor, Kazal type 1 gene, in patients with idiopathic chronic pancreatitis. Am J Gastroenterol. 2002:1133-7.

39. Pelaez-Luna M, Robles-Diaz G, Canizales-Quinteros S, TusieLuna MT. PRSS1 and SPINK1 mutations in idiopathic chronic and recurrent acute pancreatitis. World J Gastroenterol 2014; 11788-11792.

40. Rai P, Sharma A, Gupta A, Aggarwal R. Frequency of SPINK1 N34S mutation in acute and recurrent acute pancreatitis. J Hepatobiliary Pancreat Sci. 2014:663-8. 